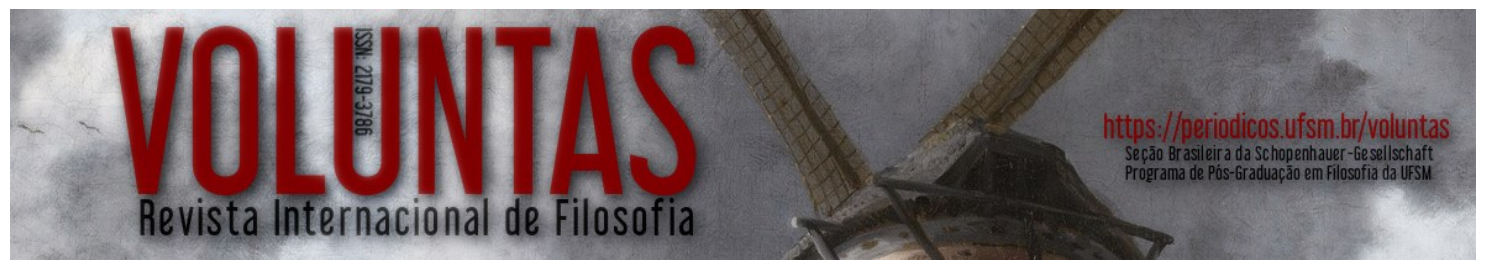

ISSN: 2179-3786

DOI: $10.5902 / 2179378633543$

\title{
Liberdade relativa e ascese: a função da razão na ética de Schopenhauer
}

\section{Relative freedom and ascesis: the function of reason in Schopenhauer's ethics}

\author{
Jarlee Oliveira Silva Salviano \\ Professor Adjunto da Universidade Federal da Babia (UFBA) \\ E-mail: jarlee.salviano@ufba.br
}

\begin{abstract}
Resumo: Na sua metafísica do belo do terceiro livro de $O$ mundo como vontade e representação, Schopenhauer defende a inutilidade do conceito para a arte, com a exceção da poesia, para a qual a palavra é a matéria-prima. No quarto livro, no entanto, assim como em seu ensaio premiado Sobre a liberdade da vontade, a razão desempenha um papel importante na constituição da moralidade. Por um lado, afirma ele (em meio à descrição mítica do redentor fenômeno da graça, que "vem de fora", através de uma "mudança no modo de conhecimento") que a redenção não nos vem através de um pretenso livre-arbítrio, não se dá por um "arbítrio ponderado (obras), mas no conhecimento (fé)". O filósofo procura manter assim sua vigorosa oposição ao racionalismo ético da deontologia kantiana. Por outro lado, a razãa (por sua capacidade de reflexão e recordação), é tomada em certos momentos como um instrumento auxiliar no processo de afirmação consciente da vontade (o caráter adquirido), bem como no próprio fenômeno da negação da vontade. Cabe verificar como se sustentam, nesta ambiguidade do estatuto da racionalidade, importantes conceitos éticos como a liberdade, a imputabilidade moral, a má consciência (remorso) etc.
\end{abstract}

Palavras-chave: Razão; Ascetismo; Liberdade relativa; Caráter.

Abstract: In his metaphysics of the beautiful of the third book of The world as will and representation, Schopenhauer defends the uselessness of the concept to the art. With the exception of poetry, for which the word is the raw material. In the fourth book, however, as in his prize-winning essay $O n$ freedom of will, the reason plays an important role in the constitution of morality. On the one hand, he affirms (about the mythical description of the redemptive phenomenon of grace, which "comes from without" through a "change in the mode of knowledge") the redemption does not come to us through a alleged free-will, that is not by a "deliberated will (works), but in knowledge (faith)". The philosopher seeks to maintain his vigorous opposition to the ethical rationalism of Kantian deontology. On the other hand, reason (by its capacity for reflection and remembrance) is taken at certain moments as an auxiliary instrument in the process of conscious affirmation of the will (the acquired character), as well as in the phenomenon of the negation of the will. It is necessary to verify how important ethical concepts such as freedom, moral imputability, bad conscience (remorse), etc. are maintained in this ambiguity of the statute of rationality.

Keywords: Reason; Asceticism; Relative freedom; Character. 



quarto Livro de $O$ mundo como vontade e representação de Schopenhauer inicia-se com o decreto que anuncia a aparente renúncia romântica e irracionalista à presença da razão na ética do filósofo. A despeito do racionalismo da ética kantiana (que o precede e lhe serve de ponto de partida), Schopenhauer declara que, em relação ao valor da existência, "os conceitos mortos da filosofia não decidem"1. E acrescenta: "A virtude é tão pouco ensinada quanto o gênio; sim, para ela o conceito é tão infrutífero quanto para a arte e em ambos os casos deve ser usado apenas como instrumento"2. Qual deve ser então este caráter instrumental da razão para a ética? Seria ela dispensável no exercício da moralidade? Algum dos três momentos da filosofia moral de Schopenhauer (a estoica liberdade relativa proporcionada pelo caráter adquirido; a moral da compaixão; e o ascetismo) poderia ser efetivo, caso haja a dispensa deste instrumento? Vejamos.

O confronto com o racionalismo do formalismo transcendental de Kant, que principia todos os escritos de Schopenhauer sobre ética, proporcionou aquele cômico episódio que envolve seu ensaio não premiado Sobre o fundamento da moral. Trata-se do desentendimento entre o autor e os pareceristas do concurso acerca da exigência da apresentação de uma fundamentação metafísica do princípio da moralidade. Schopenhauer queixa-se, na introdução do ensaio, sobre a limitação imposta pela pergunta da Sociedade Real de Ciências da Dinamarca, que, segundo ele, excluía tal fundamentação ao exigir "que o fundamento da ética seja exposto separadamente e por si só, numa monografia curta, fora, portanto, da sua conexão com o sistema de qualquer filosofia que seja, quer dizer, da metafísica propriamente dita". E isso, acrescenta Schopenhauer, "deve não só dificultar a sua realização, mas até torná-la necessariamente incompleta" 3 . Ainda assim, o filósofo gentilmente apresenta, em anexo, como um bônus, como uma opus supererogationis (obra que ultrapassa as exigências), uma Explicação metafísica do fenômeno ético originário. Por outro lado, no parecer da comissão julgadora, além da censura da Sociedade Real em relação às menções a filósofos excelentes de modo indecente e da tentativa frustrada de "constituir na compaixão o fundamento da ética" - pois o candidato não o teria provado suficientemente, admitindo na verdade o oposto (a impressão que se tem aí é que os julgadores leram somente a parte inicial do capítulo em que Schopenhauer apresenta sua ética, o das motivações antimorais, o dantesco inferno do egoísmo e da maldade) - o parecer também refere-se ao fato de que "a parte de sua dissertação em que o nexo dos princípios de ética por ele estabelecidos com a sua metafísica ocupa o lugar de um apêndice, onde ofereceria mais do que teria sido requerido, embora fosse exigida, de todo modo, a discussão do tema em que o nexo da metafísica e da ética seria o

\footnotetext{
${ }^{1}$ SCHOPENHAUER, A. MVR, p. 355.

2 SCHOPENHAUER, A. MVR, p. 355-356.

${ }^{3}$ SCHOPENHAUER, A. SFM, p. 7.
}

Voluntas: Revista Internacional de Filosofia - periodicos.ufsm.br/voluntas - Santa Maria - Vol. 9, n. 1, jan.-jun. 2018, pp. 93-103 
principal assunto a ser considerado"4. Afinal, a que se deve tal desencontro? A resposta talvez se encontre na pergunta do concurso, colocada pela Sociedade Real em 1837: "A fonte e o fundamento da filosofia da moral devem ser buscados numa ideia de moralidade contida na consciência imediata e em outras noções fundamentais que dela derivam ou em outro princípio do conhecimento?"5. Ora, a resposta direta de Schopenhauer à questão seria: nem num lugar nem em outro! Nem na consciência imediata nem na mediata. O fundamento da moral não está em nenhum princípio do conhecimento, mas num sentimento, a compaixão. Vê-se claramente que a Sociedade Real também estava assentada no confortável encosto, como diz Schopenhauer, da ética kantiana e seu Imperativo Categórico. Portanto, era inquestionável para eles que a ética devesse ser fundada em princípios da consciência, encontrados talvez de modo imediato, a priori, nalguma espécie de subjetividade transcendental.

No entanto, a crítica a este abstracionismo não conduz Schopenhauer a um irracionalismo absoluto. A eticidade inexiste, como diz o filósofo no início deste último livro de $O$ mundo, sem o autoconbecimento (conforme já nos alerta o título deste livro 4: "alcançando o conhecimento de si, afirmação e negação da Vontade de vida"(). A essência do homem, entretanto, só pode ser expressa plenamente pela concatenação das ações na experiência, a posteriori. "A conexão autoconsciente destas é possível pela faculdade da razão, que sempre lhe permite um olhar de conjunto, in abstracto, sobre o todo"7.

A distinção entre esta afirmação consciente da vontade e a afirmação cega da vontade, que decorrem da presença ou ausência daquele olhar sobre o todo (o autoconhecimento) é assim definida: "quando, em sua objetidade, ou seja, no mundo e na vida, a própria essência lhe é dada plena e distintamente como representação, semelhante conhecimento não obsta de modo algum seu querer, mas exatamente esta vida assim conhecida é também enquanto tal desejada; se até então sem conhecimento, como ímpeto cego, doravante com conhecimento, consciente e deliberadamente (mit Erkenntnis, bewusst und besonnen)"".

A negação da vontade, por outro lado, mostrar-se-á em seguida, na análise do ascetismo.

\footnotetext{
${ }^{4}$ SCHOPENHAUER, A. SFM, p. 225.

${ }^{5} \mathrm{Idem}$.

${ }^{6} \mathrm{Na}$ tradução de Jair Barboza há a substituição do conectivo "e" por “ou”. Em nota o tradutor justifica tal substituição afirmando que não se tem ao mesmo tempo, após o autoconhecimento, afirmação e negação da vontade. Entretanto, pode-se apresentar três elementos que apontam para a incorreção da modificação deste subtítulo: 1) a praga de Schopenhauer nos Parerga e Paralipomena, nos capítulos em que trata do ofício do escritor, livros e estilo (“ai daquele que mudar uma vírgula de meus escritos..."); 2. o "e" poderia representar meramente uma disposição metodológica (primeiro a exposição sobre a afirmação consciente e em seguida a exposição sobre a negação da Vontade); 3. ademais, o próprio Schopenhauer apresenta, por exemplo, o fenômeno do ascetismo como uma contradição da Vontade consigo mesma: o corpo afirma o que o conhecimento nega. O que poderia permitir sim o pensamento da concomitância de afirmação e negação da vontade.

${ }^{7}$ SCHOPENHAUER, A. MVR, p. 357.

${ }^{8}$ SCHOPENHAUER, A. MVR, p. 369.
} 
O conhecimento de si da Vontade é operado por aquele que é seu fenômeno mais perfeito, o ser humano, no qual este mekhané, o conhecimento, originariamente constituído em vista da conservação, pode elevar sua luz à percepção das formas eidéticas, no sentido platônico. A autonegação e supressão (Aufhebung) da Vontade se segue daí. No homem a Ideia é identificada ao seu caráter inteligível. $\mathrm{Na}$ afirmação cega o indivíduo fenomênico apenas reproduz nas ações o ávido e insaciável anseio do impulso cego e irracional da Vontade. Ele é um caráter empírico determinado pela força dos motivos. O caráter empírico é a expressão fenomênica do caráter inteligível. A lei da motivação (a quarta raiz do princípio de razão suficiente) determina infalivelmente a ação animal no mundo como representação, do mesmo modo como as três outras formas de causalidade determinam: a natureza orgânica e inorgânica; a representação abstrata (lógica); e os objetos matemáticos (aritmética e geometria). Na afirmação da Vontade, seguimos naturalmente nosso demônio (Dämon) interior, como já anunciava Platão, aqui mencionado e resignificado por Schopenhauer, já que nosso daimon é a vontade cega e irracional.

Indiferente a isto, a Vontade noumênica é absolutamente livre, assim como o sujeito puro do conhecimento, suporte de todo este mundo como representação, como quer o idealismo schopenhaueriano. O caráter inteligível é o "ato extratemporal, indivisível e imutável da Vontade" e, portanto, livre. Schopenhauer defende aqui a asseidade da Vontade ${ }^{10}$ e repele a ideia do liberum arbitrium indifferentiae, um arbítrio da consciência empírica que principiaria por si mesmo uma ação, a despeito da determinação dos motivos. Em suma, o caráter empírico é sempre determinado pelos motivos (o objeto espaço-temporal, alvo das inclinações), mas a liberdade da Vontade como coisa-em-si pode inocular-se no mundo fenomênico através da autonegação desta. Como não é possível um conhecimento imediato do caráter inteligível, a decisão diante de uma situação de escolha só é conhecida a posteriori, empiricamente. É esta experiência empírica do caráter e a reflexão sobre a efetivação das ações no tempo que permite um conhecimento o mais claro possível de nossa essência, a partir da qual queremos ou não queremos sempre o mesmo em cada situação: o que nos possibilita alcançar uma clarez̧a de consciência (Besonnenheit), um caráter adquirido ${ }^{11}$.

\footnotetext{
${ }^{9}$ SCHOPENHAUER, A. MVR, p. 375.

${ }^{10}$ Não ser determinada por nada, responsável por sua própria existência. Cf. SCHOPENHAUER, A. N, p. 210.

11 Ocorre a Schopenhauer o feliz encontro no Bhagavad Gita de uma trina disposição do caráter, os três Gunas (modos), que podem ser aproximados às três disposições práticas fundamentais (afirmação cega; afirmação consciente; e negação da Vontade): Radja-Guna (querer violento, grandes paixões); Tama-Guna (letargia da vontade e o conhecimento a ela associado, anelar vazio, tédio petrificante: liberdade relativa/decisão eletiva); e Sattva-Guna (inteligência liberta do serviço da vontade, gênio) (SCHOPENHAUER, A. MVR, p. 413-414). Em Sobre a vontade na Natureza são ainda apresentadas as três potências fisiologicas fundamentais bem como as expressões políticas exemplares desta tríade: 1. da irritabilidade (músculos) advém a aptidão para esforços corporais (Espartanos); 2. da primazia da produtividade (tecido celular) no ser orgânico se tem um caráter fleugmático (Beócios); 3. e da sensibilidade (nervos) - o cérebro é o centro do sistema nervoso - tem-se o indivíduo de gênio (Atenienses).
}

Voluntas: Revista Internacional de Filosofia - periodicos.ufsm.br/voluntas - Santa Maria - Vol. 9, n. 1, jan.-jun. 2018, pp. 93-103 
Esta ponderação racional (vernünftige Überlegung) do caráter adquirido torna possível, de um lado, o esclarecimento dos motivos existentes, a percepção mais acurada das motivações empíricas que se apresentam como objeto de satisfação da atividade apetitiva do sujeito, a colocação às claras de um contexto que, em outra circunstância, não teria excitado assim o querer tal como o faz no momento presente, devido a uma ilusão qualquer ocasionada pela deficiente perspectiva que relaciona sujeito e objeto. Por outro lado, a razão pode oferecer outras motivações, conceitos abstratos, contramotivos que irão rivalizar com as representações empíricas (tomadas in abstracto). E neste conflito dos motivos (Konflikt der Motive), neste campo de batalha (Kampfplatz), a vontade pode (mera possibilidade) alterar seu rumo - mas o caráter mesmo permanece inalterável. É isto o que Schopenhauer chama (em O mundo) de escolha eletiva (Wablentscheidung) - que será expressa posteriormente (no ensaio premiado Sobre a liberdade da vontade) como liberdade relativa. Pela instrução, portanto, muda-se os meios, nunca os fins ou o ser mais íntimo que os persegue: velle non discitur (o querer não se aprende), diz a fórmula de Sêneca diversas vezes citada por Schopenhauer ${ }^{12}$. Ademais, ao passo que as representações abstratas podem ser o antídoto mais ou menos eficiente para a questão da decisão moral (e a consequente felicidade relativa advinda daî), elas também podem ser o veneno a provocar sofrimentos espirituais intensos, que em alguns casos pode levar ao suicídio.

As psicologias racionais que estipulavam a existência do livre arbítrio amparavam-se na convicção de que, pela alma, primeiro conheceríamos uma coisa como boa e em seguida quereríamos esta coisa. Ao passo que em Schopenhauer se dá o contrário: primeiro o querer, depois a consideração como boa, pelo conhecimento. "Pela citada tradição", diz o filósofo, "ele QUER o que conhece; em mim ele CONHECE o que quer"13. Em Sobre a liberdade da vontade a peculiar ironia do autor nos oferece a seguinte ilustração da ilusão do livre arbítrio:

Para elucidar de modo especial e o mais claro possível a origem deste erro
tão importante para nossa tese, e completar com isso o estudo do
testemunho da consciência que iniciamos no capítulo precedente,
imaginemos um homem que, encontrando-se por exemplo na rua, dissesse
a si mesmo: "São seis horas da tarde, meu dia de trabalho terminou. Eu
posso agora fazer um passeio ou ir ao cassino; posso também subir numa
torre para ver o pôr-do-sol; posso também ir ao teatro, ou fazer uma visita

${ }^{12}$ Poderíamos afirmar que presenciamos aí a antecipação da tese psicanalítica da sublimação? Certamente, e diante disto deveria talvez ser corrigida uma nota de Paulo César de Souza em sua tradução de Além de Bem e Mal de Nietzsche, em que o tradutor (citando Walter Kaufmann) observa que ali, pela primeira vez, aparece o conceito psicanalítico de sublimação (Sublimierung) (NIETZSCHE, F. W. ABM, p. 237). Pois em Schopenhauer, nos Parerga, esta ideia do desvio dos impulsos já se faz presente: "É o persistente amor aos prazeres do mundo, que quer sobreviver a si mesmo, a completa inconvertibilidade, o prazer carnal sublimado (sublimiert) e intelectualizado, $\mathrm{o}$ foco abstrato em que se reúnem todas as alegrias, em relação às quais ele consequentemente se compota como o conceito geral em relação às coisas particulares (SCHOPENHAUER, A. PP, p. 48-49).

${ }^{13}$ SCHOPENHAUER, A. MVR, p. 379. 
a um amigo ou a outro; eu posso até mesmo atravessar os portões da cidade e me lançar no meio do vasto universo e nunca mais voltar [...]. Tudo isto só depende de mim, eu tenho a plena liberdade de agir como me apraz. E, entretanto, eu não farei nada disso, mas vou voltar, não menos voluntariamente, para casa, para junto de minha mulher". É exatamente como se a água dissesse: "Posso me elevar bruscamente em altas ondas (sim, certamente, quando o mar é agitado por uma tempestade!), - posso descer em um ritmo vertiginoso levando tudo em meu caminho (sim, no leito de uma correnteza), - posso cair num tumulto de espumas (sim, numa cachoeira) - posso me elevar no ar, livre como um raio (sim, em uma fonte), - posso enfim evaporar e desaparecer (sim, a 100 graus de temperatura); e entretanto eu não faço nada disso, mas permaneço inerte, tranquila e límpida, no espelho do lago ${ }^{14}$.

Essencial para a compreensão desta tese schopenhaueriana do caráter adquirido e o papel da razão em sua ética é a distinção entre o arrependimento (ou remorso, Reue) e o peso na consciência (Gewissensangst ou Seelenangst). O primeiro é a angústia pelo que se fez; o segundo, pelo que se quis. O arrependimento é o sintoma da correção do intelecto a respeito da ação cometida, pela escolha dos meios, que poderiam ser diferentes, caso uma clareza maior de consciência houvesse possibilitado a adequação do motivo certo com o querer: "numa palavra, agi sem ponderação, determinado não por motivos distintamente conhecidos in abstracto, mas por simples motivos intuitivos, pela impressão do presente e o afeto que este provocou, o qual foi tão violento que me privou do uso propriamente dito da razão"15. Do mesmo modo como na natureza o conflito das forças naturais impedem a irrupção da Vontade em formas perfeitas e belas - cabendo ao gênio a correção, a captação na completude daquilo que a natureza apenas balbuciou - assim também o arrependimento é uma tal correção no âmbito da moralidade ${ }^{16}$. Por outro lado, o peso na consciência é a dor pelo conhecimento claro de nossa essência imutável, de nosso caráter inteligível, e a constatação de que, dadas as circunstâncias, agiremos sempre do mesmo modo, sempre seremos determinados pelo mesmo querer. Em outras palavras, o arrependimento diz respeito ao operari; o peso na consciência ao esse - segundo a fórmula escolástica também abundantemente citada por ele: operari sequitur esse (o agir segue-se do que se é).

Cabe observar que somente o fenômeno do peso na consciência, a angústia advinda da clara consciência do que se é (do esse e não do operari) tem valor moral na ética da virtude de Schopenhauer (como bem mostra Giacóia em seu artigo na Revista

\footnotetext{
${ }^{14}$ SCHOPENHAUER, A. ELV (trad. francesa: Essai sur le libre arbitre), p. 83-84.

15 SCHOPENHAUER, A. MVR, p. 383.

${ }^{16}$ Conforme a poética palavra da cantora curitibana Hellen Carvalho, no panfleto de seu disco O grito: "o objetivo da arte não é mostrar a vida como ela é, e sim, como poderia ser, e ao despir preconceitos e inutilizar clichês saímos da automação" (CARVALHO, H. O Grito).
} 
Voluntas, vol. 7 n. 2, Ser e sentido: o paradoxo do sofrimento). Como Kant, o autor de $O$ mundo contrapõe-se a toda ética consequencialista, como o utilitarismo, para as quais o valor moral está na própria ação. Mas diferentemente de Kant, não adere à fundamentação deontológica deste, à concepção de virtude como puro respeito à lei moral. A versão schopenhaueriana do fato da razão pura prática kantiana é pois o peso na consciência, não a percepção intelectual do fato da liberdade e da lei moral, mas a angústia, a dor, pela consciência adquirida da inalterabilidade do caráter ${ }^{17}$.

Em Sobre o fundamento da moral Schopenhauer trata do remorso quando confronta a visão cética, para a qual toda a labuta dos filósofos na busca de uma fundamentação natural ou humana da moralidade teria sido em vão, ou seja, não haveria uma significação moral no mundo ${ }^{18}$. Aceita que de fato muitas ações tomadas como genuinamente morais na verdade são motivadas pelo temor do Estado ou da religião. No entanto, pergunta o filósofo, a chamada "consciência moral" (Gewissen) (como querem em geral os moralistas) poderia se apresentar como o sinal inegável da autêntica moralidade desinteressada? $\mathrm{Na}$ verdade, como procura mostrar Schopenhauer, esta inquietação oriunda da reprovação interna daquilo que se fez "não é no fundo outra coisa senão o temor daquilo que lhes pode, em virtude de tal fato, acontecer" ${ }^{\prime 19}$. Antecipando a concepção do superego freudiana e a internalização das proibições externas, Schopenhauer sentencia que "muitos ficariam admirados se vissem do que se compõe sua consciência moral, que lhes aparece tão imponente: aproximadamente um quinto de temor aos homens, um quinto de temor aos deuses, um quinto de preconceito, um quinto de vaidade e um quinto de costume"20.

Enfim, diferentemente da liberdade relativa proporcionada pelo caráter adquirido, a liberdade absoluta advinda da negação da vontade (como no caso do asceta) se apresenta num outro registro: não se trata mais de um mero conflito entre motivos abstratos: estes não têm mais qualquer serventia no estado de negação da vontade. Cabe verificar se a virtude da compaixão também pode ser entendida, de certo modo, a partir deste último registro, como negação da vontade, tendo em vista ser sua motivação não mais determinada pela representação abstrata, mas pela intuição direta do sofrimento alheio e a identificação metafísica com a essência do outro: identificação que dispensa o longo processo de

\footnotetext{
17 Rogério Lopes, em seu artigo Há espaço para uma concepção não moral da normatividade prática em Nietasche? (Cadernos Nietzsche, 33), mostra em que sentido o retorno em Nietzsche de uma ética da virtude (como se via entre os antigos), que se contrapunha às éticas deontológicas (Kant) e utilitaristas, influenciará decisivamente o panorama da ética da segunda metade do século XX. Trata-se de fundar a moralidade não no dever diante de uma lei moral divina ou dada a priori na consciência, nem num cálculo utilitarista da ação mesma, mas numa disposição do agente moral, que torna, pois, a ação necessariamente valorosa. Cumpre talvez observar que em Schopenhauer, em sua contraposição a Kant e ao utilitarismo, temos já o retorno a esta ética da virtude.

${ }_{18}$ Nos Parerga esta crítica à visão cética ganha um tom mais dramático: aquele que recusa perversamente a significação moral do mundo é o próprio “anticristo". Nietzsche será aquele que assumirá o epíteto schopenhaueriano, negando a significação moral do mundo, ao escrever seu Anticristo.

19 SCHOPENHAUER, A. SFM, p. 115.

${ }^{20}$ SCHOPENHAUER, A. SFM, p. 116.
} 
observação e reflexão sobre a efetivação das ações no tempo. Diz o filósofo, diferenciando a afirmação consciente e a negação da vontade:

Por conseguinte, até o ponto mencionado, não além, vai a diferença que a
razão ou conhecimento intermediado por conceitos produz entre o querer
humano e o querer animal. Contudo, pode se dar um acontecimento de
outra natureza, concernente à vontade humana e impossível na
animalidade, quando o homem abandona todo o conhecimento das coisas
isoladas enquanto tais, submetido ao princípio de razão, por intermédio
do conhecimento das Ideias, olha através do principium individuationis. Aqui,
de fato, é possível uma entrada em cena da liberdade propriamente dita da
Vontade como coisa-em-si, com o que o fenômeno se põe numa certa
contradição consigo mesmo, tal qual expressa pela palavra auto-
abnegação e que, em última instância, pode chegar à supressão do em-si
do seu ser [meu negrito] ${ }^{21}$.

Ora, se o abandono do conhecimento das coisas (ou pessoas) isoladas, na sua relação causal com outras coisas (ou pessoas), o olhar através (durch) do principium individuationis, o conhecimento das Ideias, significam já uma negação do desígnio imperioso da Vontade (que antes produzia o conhecimento como mero instrumento para a construção representacional da realidade), representam uma negação subversiva de sua função originária, poder-se-ia então perguntar: o fenômeno da compaixão, assim como o fenômeno da contemplação estética, não seriam já uma atividade de negação da Vontade, ainda que uma negação incompleta da Vontade? Nesta alteração fundamental no sujeito do conhecimento (mesmo que o Véu de Maya não tenha sido, neste estado intermediário, completamente descerrado) não deveria já apropriadamente ser utilizada a expressão "negação incompleta da Vontade"?

De fato, visto do ponto de vista objetivo, ou seja, da motivação, somente no ascetismo teríamos uma ação não movida por motivos, daí a saída encontrada por Selma Bassoli ao designar o fenômeno da compaixão como "afirmação atenuada da Vontade"22 - incluindo aí talvez a estoica Besonnenheit, pois já é uma afirmação atenuada, diante da afirmação cega da Vontade. No entanto, o próprio Schopenhauer nos indica a possibilidade da interpretação subjetiva, em relação à modificação no sujeito do conhecimento, que já começa a ser notada na renúncia estoica da ação movida por afetos, determinada pela força do querer cego: "Caso tenhamos investigado onde se encontram nossos pontos fortes e fracos", diz ele, referindo-se ao caráter adquirido, "desenvolveremos, empregaremos, usaremos de todas as maneiras os nossos dons naturais mais destacados e sempre nos direcionaremos para onde são proveitosos e valiosos, evitando por inteiro e com auto-abnegação aqueles

21 SCHOPENHAUER, A. MVR, p. 389.

${ }^{22}$ BASSOLI, S. A negação da Vontade e o ponto de ebulição da água, p. 12. 
esforços em relação aos quais temos pouca aptidão natural" 23 . Sendo assim, visto deste ponto de vista, da alteração da atividade cognitiva no sujeito, com a exceção da afirmação cega da Vontade, todas as outras tipologias descritas no quarto livro de $O$ mundo seriam fenômenos de negação, supressão e silêncio da Vontade (ou seja, são já modos de Quietismo), diferenciando-se apenas em graus: teríamos o grau máximo na negação absoluta da Vontade, na ascese.

Ao iniciar a discussão sobre a virtude da justiça no parágrafo 60 de $O$ mundo, Schopenhauer assim caracteriza a AFIRMAÇÃO DA VONTADE: "é o constante querer mesmo, não perturbado por conhecimento algum, tal qual preenche a vida do homem em geral"24. E mais adiante, distinguindo esta afirmação recém-analisada nos parágrafos anteriores (bem como o sofrimento e o tédio originados desta afirmação) daquilo que se seguirá então: "É sempre uma exceção se um semelhante decurso de vida sofre uma interferência e, devido a um conhecer independente do serviço da vontade e direcionado à essência do mundo em geral, conduz à demanda pela contemplação estética ou à demanda pela renúncia ética"25.

E ainda, a respeito desta modificação do sujeito e a "completa supressão da Vontade quando os motivos se tornam impotentes" no asceta, diz o filósofo, o estado no qual o caráter não é determinado por motivos não procede "imediatamente da Vontade, mas de uma forma modificada de conhecimento". E conclui:

\footnotetext{
Assim, enquanto o conhecimento é envolto no principio individuationis e segue de maneira absoluta o princípio de razão, o poder dos motivos é também irresistível; quando, entretanto, se olha através do principium individuationis, quando as Ideias, sim, a essência da coisa-em-si, é imediatamente reconhecida como a mesma Vontade em tudo e, a partir desse conhecimento, resulta um quietivo universal do querer, então os motivos individuais se tornam sem efeito, porque a forma de conhecimento correspondente a eles é obscurecida e posta em segundo plano por um conhecimento por inteiro diferente ${ }^{26}$.
}

Portanto, todos os critérios de determinação da negação da Vontade no asceta se verifica também, em certo grau, na ação compassiva e na afirmação consciente do estoico: são "conhecimentos diferentes", mas não "por inteiro diferentes" (como na ascese).

Por outro lado, o que nos resta ainda problemático é a inserção, no penúltimo parágrafo de $O$ mundo, da Besonnenheit (a clareza de consciência) como uma ferramenta

\footnotetext{
${ }^{23}$ SCHOPENHAUER, A. MVR, p. 394, grifo meu.

${ }^{24}$ Idem, p. 420.

${ }^{25}$ Idem, p. 420-421, grifos meus.

${ }^{26}$ Idem, p. 409, grifo meu.
} 
auxiliar da liberdade absoluta do asceta conquistada pela negação da vontade, que aqui é equiparada ao EFEITO DA GRAÇA do cristianismo:

\begin{abstract}
Pois exatamente aquilo que os místicos cristãos denominam EFEITO DA GRAÇA e RENASCIMENTO é para nós a única e imediata exteriorização da LIBERDADE DA VONTADE. Esta só entra em cena quando a Vontade, após alcançar o conhecimento de sua essência em si, obter dele um QUIETIVO, quando então é removido o efeito dos MOTIVOS, os quais residem em outro domínio de conhecimento cujos objetos são apenas fenômeno. - Portanto, a possibilidade de a liberdade exteriorizar-se a si mesma é a grande vantagem do homem, ausente no animal, porque a condição dela é a clarividência da razão [Besonnenheit der Vernunff], que o habilita a uma visão panorâmica do todo da vida, livre da impressão do presente. $\mathrm{O}$ animal está destituído de qualquer possibilidade de liberdade, assim como da possibilidade de uma real, logo com clareza de consciência, decisão eletiva segundo um prévio e completo conflito de motivos, que para tal fim teriam de ser representações abstratas ${ }^{27}$.
\end{abstract}

A estranheza de tal ressurgimento da razão no discurso sobre o ascetismo se deve a que Schopenhauer esteve já nos convencendo há alguns parágrafos que o caminho para a ascese se dava pela intuição (o conhecimento direto, não conceitual): ou da dor alheia (o sofrimento universal) ou da dor própria (a "segunda navegação" para a ascese, diz o filósofo), como vemos em seguida naquele mesmo parágrafo 70 , no instante de seu flerte com Lutero: "Noutros termos, vemos que a genuína virtude e a santidade de disposição tem sua primeira origem não no arbítrio ponderado (obras), mas no conhecimento (fé)"28.

Enfim, não esperávamos este retorno à Besonnenheit, pois já tínhamos nos despedido dela no instante em que Schopenhauer conclui, no quarto Livro de O mundo, sua análise do caráter adquirido: "é o suficiente sobre o CARÁTER ADQUIRIDO, que é importante não tanto para a ética como para a vida no mundo"29.

\title{
Referências bibliográficas
}

BASSOLI, S. A negação da Vontade e o ponto de ebulição da água. Revista Voluntas: Estudos sobre Schopenhauer, Rio de Janeiro, v. 1, n. 1, $1^{\circ}$ semestre de 2010, pp. 6-18.

CARVALHO, H. O Grito. Curitiba, Novodisc Mídia Digital, 2016. 1 CD.

GIACÓIA JR., O. Ser e sentido: o paradoxo do sofrimento. Revista Voluntas: Estudos sobre Schopenhauer, Rio de Janeiro, v. 7, n. 2, $2^{\circ}$ semestre de 2016, pp. 4-26.

\footnotetext{
${ }^{27}$ SCHOPENHAUER, A. MVR, p. 510.

28 SCHOPENHAUER, A. MVR, p. 513.

${ }^{29}$ SCHOPENHAUER, A. MVR, p. 396.
} 
LOPES, R. Há espaço para uma concepção não moral da normatividade prática em Nietzsche? Cadernos Nietzsche, São Paulo, n. 33, 2013, pp. 89-134.

NIETZSCHE, F. W. Além do bem e do mal: prelúdio a uma filosofia do futuro. Trad. Paulo César de Souza. São Paulo: Companhia das letras, 1992.

SCHOPENHAUER, A. Sämtliche Werke. Textkritisch bearbeitet und herausgegeben von Wolfgang Frhr. Löhneysen. Darmstadt: Wissenschaftliche Buchgesellschaft, 1968.

SCHOPENHAUER, A. Essai sur le libre arbitre. Trad. Salomon Reinach. Paris: Félix Alcan, 1925.

SCHOPENHAUER, A. O mundo como vontade e representação. Trad. Jair Barboza. São Paulo: Unesp, 2005.

SCHOPENHAUER, A. Sobre a ética (parágrafos 108 a 182 dos Parerga e Paralipomena). Trad. Flamarion Caldeira Ramos. São Paulo: Hedra, 2012.

SCHOPENHAUER, A. Sobre a vontade na natureza. Trad. Grabriel Valadão. Porto Alegre: L\&PM, 2013.

SCHOPENHAUER, A. Sobre o fundamento da moral. 2. ed. Trad. Maria Lúcia Mello e Oliveira Cacciola. São Paulo: Martins Fontes, 2001. 